\title{
Female sexual function in users of combined oral and traditional contraceptive methods
}

\author{
MITRA TADAYON ${ }^{A, D, F}$, PARVANEH MOUSAVI ${ }^{B}$, ZAHRA ABBASPOOR $^{\mathrm{D}-\mathrm{F}}$ \\ ORCID ID: 0000-0001-8095-096X
}

Midwifery Department, Reproductive Health Promotion Research Center, Ahvaz Jundishapur University of Medical Sciences, Ahvaz, Iran

A - Study Design, B - Data Collection, C - Statistical Analysis, D - Data Interpretation, E - Manuscript Preparation, F - Literature Search, G - Funds Collection

Summary Background. Combined oral contraceptive pills containing ethinyl estradiol and levonorgestrel are the most common contraceptives that are used by women of the reproductive age. Moreover, sexual function is linked to sexual hormones. Objectives. The aim of this study was to evaluate the sexual function of hormonal contraceptive (OCP) and non-hormonal contraceptive (traditional or withdrawal) methods in Iranian reproductive-age women referred to healthcare centers.

Material and methods. This was a cross-sectional study on 206 married women of the reproductive age (18-45). Ninety-six women used OCP to prevent pregnancy, and 110 women did not use any contraceptives, instead using a traditional (withdrawal) method for at least 6 months before the study. Data on sexual function was collected via the Female Sexual Function Index (FSFI) questionnaire. The independent $t$-test was used for statistical purposes.

Results. The results showed that there were no significant differences in all domains of sexual function in the two groups, except in the area of sexual arousal ( 3.87 in OCP users and 4.14 in withdrawal user methods) $(p<0.05)$. There was an association between the arousal domain and oral contraceptive use, but there was no relation between OCP and other domains of sexual function.

Conclusions. The combined oral and withdrawal contraceptive methods have no impact on sexual function, except in the area of sexual arousal.

Key words: contraception, sexuality, women.

Tadayon M, Mousavi P, Abbaspoor Z. Female sexual function in users of combined oral and traditional contraceptive methods. Fam Med Prim Care Rev 2019; 21(1): 58-61, doi: https://doi.org/10.5114/fmpcr.2018.79990.

\section{Background}

There is a strong association between sexual well-being and overall life satisfaction of individuals over time, and sexual problems have negative impacts on emotional well-being [1]. Female sexual dysfunction (FSD) is defined as psychophysiological changes and disturbances in sexual desire, which cause marked distress and interpersonal difficulty [2]. An estimation of the prevalence of sexual dysfunction in women is difficult, because the parameters of female sexual dysfunction are not very clear [3], but it is considered to be about $40 \%$, taking into account at least one sexual dysfunction [4]. Sexual dysfunction has been especially linked to emotional intimacy [5] and sexual hormones [6].

Studies have shown a reduction in sexual desire and interest in sex with menopause and aging [7]. Women in the reproductive age are under psychological, socio-cultural and relationship influences, as well as the influence of sex hormones [3], including estrogens, androgens and progestin, with different effects on the vaginal tissue and the central nervous system [6]. In the liver, oral contraceptives induce Sex Hormone Binding Globulin (SHBG), which transports protein for sex hormones [8] and can be enhanced or reduced by adding progestin. SHBG can reduce free testosterone levels, as well as ethinyl estradiol and progestin, as some androgenic and antiandrogenic properties can influence serum SHGB levels and, thus, female sexual function. Estrogens have a significant role in maintaining the vaginal epithelium, as well as the blood flow of the genital tract [9]. Androgens have an important role in female sexual function and dysfunction and are used for the treatment of some sexual dysfunctions in women [10]. Oral contraception (OC) is a common method of contraception in the United States, used by $50 \%$ of contraceptive users under 25 years of age. Oral contraceptives have good efficacy with a typical failure rate (9\%) annually [11]. Moreover, oral contraception has also been suggested as a possible modulator of female sexual function [12], but it is commonly believed that combined oral contraceptive pills containing ethinyl estradiol and levonorgestrel have a negative effect on sexual function in women. However, the effects remain unclear [13]. The traditional method (withdrawal) is one of the oldest forms of contraception and, before industrialization in Europe, it played a major role in the decline of the population. Although some couples are satisfied using this method, others find it difficult. It seems that this method is still widely used, especially in Iran. As a contraceptive, the withdrawal method, when used in the right manner, is effective in $81-96 \%$ of cases [14] with a $4 \%$ failure rate [15]. In a study conducted in Tabriz, Iran, the most common reasons for using the withdrawal method included: ensuring the effectiveness of the method (31.3\% of cases), fear of infertility (29.5\% of cases) and the husband's unwillingness to use other methods (16.6\% of cases) [16]. Considering the high use of the withdrawal method in Iran and limited studies regarding the relationship between the use of traditional methods and sexual function, and also the relationship between oral contraception use and sexual function among Iranian women, this study aimed at comparing the female sexual function of combined oral and traditional contraceptive method users referred to healthcare centers.

\section{Material and methods}

This was a cross-sectional study on 206 married women in their reproductive age that used oral contraceptive or tradition- 
al methods (withdrawal) as contraception. The study, done in two healthcare centers in Ahvaz, Iran, started in October 2013 and ended in March 2014.

The ethics committee of the Ahvaz Jundishapur University of medical sciences approved the study with the reference code: IR.AUJMS.REC.1392.343. All participants gave their permission by signing an informed consent form before entering the study.

Considering the prevalence of the OCP method $31 \%$ of cases) and the withdrawal method (37.8\% of cases) with a 0.95 confidence interval and a 0.05 error, power $90 \%$, and considering a $10 \%$ likely drop, the sample number for the OCP group was 96 (who used OCP as a contraceptive at least for 6 months), and for the traditional method (withdrawal), this was was 110 who did not use any barrier methods. Two healthcare centers were selected randomly, and women who met the study's eligibility criteria were explained the nature of the study and were invited to fill out the questionnaires. The inclusion criteria consisted of the following: women who got married at least two years before, women who were aged between 18 and 45 years and had a sexual relationship, had not undergone any surgery on their genitalia, such as hysterectomy or vaginoplasty, and used the LD contraceptive pill ( $30 \mu \mathrm{g}$ ethinyl estradiol + $0.3 \mathrm{mg}$ levonorgestrol) or the withdrawal method continually for the previous 6 months. The exclusion criteria included the following: women who were pregnant, who were under treatment for infertility and who were taking medication that affects sexual function, e.g. antihypertensive drugs or antidepressants, those whose husbands had a history of sexual disorders and those who used two or more contraceptive methods at the same time. Data was collected in one menstrual cycle for every woman. Prior to the commencement of the study, a written informed consent was obtained from each participant, and their anonymity was preserved. Data was collected using a socio-demographic questionnaire and the Female Sexual Function Index (FSFI) questionnaire. The socio-demographic questionnaire included demographic characteristics, including age, couple's age difference, marriage date and educational level (primary school, high school or university graduation). The FSFI questionnaire contained 19 questions, including 2 questions concerning the libido area, 4 questions about the sexual arousal domain, 4 questions on the lubrication domain and 3 questions each for orgasm, sexual satisfaction and pain. Mohammadi et al. validated the Persian version of this questionnaire [17]. A five-point Likert scale was used for scoring. The score of each domain was multiplied by a certain factor. The factor for desire was 0.6 , for arousal and lubrication -0.3 , and for other domains -0.4 . The minimum and maximum score for the FSFI were 2 and 36, respectively. The cutoff point for the total scale was 28.

\section{Statistical methods}

All statistical analyses were done using SPSS, version 19. An independent $t$-test was used to compare sexual function scores.

\section{Results}

The mean age of women in the OCP user group was 29.71, and in the withdrawal group, it was 28.85 years, and the mean age of the spouses was 33.78 and 34.07 years in the OCP and the withdrawal group, respectively. There were no significant differences in the basic characteristics in the OCP and withdrawal user groups. Only in the case of the number of children, the average number of children in the OCP user group (1.38) was more than in the withdrawal user group (0.98) $(p<0.004)$, and, by using covariate analysis, the effect of the number of children as a confounding variable was assessed, and, with $p=0.328$, the results showed no effect on the two groups' relationship. The socio-demographic characteristics of the participants are listed in Table 1.
Table 1. Socio-demographic characteristics of OCP users' and withdrawal users' groups $(n=206)$

\begin{tabular}{|c|c|c|c|}
\hline Characteristic & $\begin{array}{l}\text { OCP users } \\
(n=96) \\
\text { Mean } \pm \text { SD }\end{array}$ & $\begin{array}{l}\text { Withdrawal } \\
\text { users } \\
(n=110) \\
\text { Mean } \pm \text { SD } \\
\end{array}$ & $p$ \\
\hline Age, y (female) & $29.71 \pm 6.19$ & $28.85 \pm 6.87$ & 0.354 \\
\hline Age, y (male) & $33.78 \pm 7.20$ & $34.07 \pm 7.16$ & 0.770 \\
\hline Marriage date & $2.04 \pm 1.01$ & $1.93 \pm 1.05$ & 0.43 \\
\hline Number of children & $1.38 \pm 0.91$ & $0.98 \pm 1.04$ & $0.004 *$ \\
\hline $\begin{array}{l}\text { Duration of using of } \\
\text { contraceptive }\end{array}$ & $2.02 \pm 0.85$ & $2.14 \pm 0.85$ & 0.338 \\
\hline $\begin{array}{l}\text { Level of education } \\
\text { (female), } \boldsymbol{n}(\%) \\
\text { Primary school } \\
\text { High school } \\
\text { University }\end{array}$ & $\begin{array}{l}6(6.4) \\
34(36.2) \\
54(57.4)\end{array}$ & $\begin{array}{l}4(3.6) \\
44(40) \\
62(56.4)\end{array}$ & 0.624 \\
\hline $\begin{array}{l}\text { Occupational status, } \\
\boldsymbol{n}(\%) \\
\text { Employed } \\
\text { Unemployed }\end{array}$ & $\begin{array}{l}35(37.2 \%) \\
59(62.8 \%)\end{array}$ & $\begin{array}{l}27(24.5 \%) \\
83(75.5 \%)\end{array}$ & 0.050 \\
\hline $\begin{array}{l}\text { Financial situation } \\
\text { Low } \\
\text { Moderate } \\
\text { Good }\end{array}$ & $\begin{array}{l}28(29.8 \%) \\
51(54.3 \%) \\
15(16 \%)\end{array}$ & $\begin{array}{l}41(37.3 \%) \\
55(50 \%) \\
14(12.7 \%)\end{array}$ & 0.499 \\
\hline
\end{tabular}

*Significant differences in number of children in OCP users' and withdrawal users' groups.

According to Table 2, there was no significant difference between the two groups in all the aspects of sexual function, except for sexual arousal $(p<0.001)$. Sexual function, in all domains except sexual arousal, showed no significant differences between the two groups. In sexual arousal, a significant difference was observed between the two groups ( 3.87 for OCP users and 4.14 for withdrawal users).

\begin{tabular}{|c|c|c|c|}
\hline Domains & $\begin{array}{l}\text { OCP users } \\
(n=96) \\
\text { Mean } \pm \text { SD }\end{array}$ & $\begin{array}{l}\text { Withdrawal users } \\
(n=110) \\
\text { Mean } \pm \text { SD }\end{array}$ & $p$ \\
\hline Desire & $3.71 \pm 1.04$ & $3.88 \pm 0.97$ & 0.233 \\
\hline Arousal & $3.87 \pm 0.85$ & $4.14 \pm 0.97$ & $0.039 *$ \\
\hline Lubrication & $4.03 \pm 0.99$ & $4.00 \pm 1.05$ & 0.853 \\
\hline Orgasm & $4.35 \pm 1.02$ & $4.48 \pm 1.12$ & 0.404 \\
\hline Satisfaction & $4.83 \pm 0.98$ & $5.04 \pm 1.04$ & 0.141 \\
\hline Pain & $4.57 \pm 1.08$ & $4.50 \pm 1.18$ & 0.689 \\
\hline $\begin{array}{l}\text { Total Score } \\
\text { (FSFI) }\end{array}$ & $25.35 \pm 3.76$ & $26.05 \pm 4.43$ & 0.222 \\
\hline
\end{tabular}

* There is a significant difference only in the area of sexual arousal.

\section{Discussion}

The results indicate that the combined oral and withdrawal contraceptive methods have no impact on sexual function, except in the area of sexual arousal, where oral contraceptives can reduce the arousal phase in the users.

Sexual arousal disorder is the absence of or markedly reduced feelings of sexual arousal, including sexual excitement and pleasure from any kinds of sexual stimulation [18]. Lack of sex hormones, such as estrogen, can be one of the factors influencing sexual arousal, as shown in hypothalamic amenorrhea, during postpartum lactation amenorrhea and the menopausal 
period. Hormonal contraceptives can also cause a disorder in genital arousal, as well vaginal dryness [4]. In the present study, sexual arousal was different among the oral combined contraceptive users and withdrawal users. Malmborg et al., in a study on young women, reported women using hormonal contraception were more likely to experience reduced sexual desire compared to women using hormone-free contraception [19, 20]. The use of OCP is associated with a decrease in androgen ovarian synthesis and an increase in the production of sex hormonebinding globulin (SHBG) $[4,11]$. Warnock et al. indicated that combined oral contraceptives (COCs) used by reproductive-age women who have hypoactive sexual desire disorder are associated with lower free and total testosterone levels than those who do not use COCs [21]. Testosterone levels are reported to vary between 0.42 and $2.94 \mathrm{nmol} / \mathrm{l}$ in healthy women, and the ovary and the adrenal gland each secrete about $25 \%$ of testosterones [22]. Graziottin et al. reported that more than $50 \%$ of androgens are contributed by the ovaries during reproductive life [4]. Moreover, medication or conditions that increase the sex hormone binding globulin (SHBG) can decrease testosterone [23]. Zimmerman et al., in a review study, reported that COCs decrease the circulating levels of total and free testosterone and increase SBHG concentrations. With an increase in the SHBG level, free testosterone levels decrease twice as much as that of total testosterone. The estrogen and progestin of the COC do not influence the decline of total and free testosterone, but both affect SHBG [22]. The sexual cycle starts with the desire phase, which is modulated in the brain by a balance of the dopamine and serotonin centers [19], and testosterone responds to changes in these centers [3]. Studies have shown that all the conditions that reduce the level of androgens, such as aging, oophorectomy, chemotherapy or radiation to the pelvis, reduce sexual desire and libido [23].

\section{Conclusions}

The combined oral contraceptive method (as a hormonal method), as well as withdrawal contraceptive method (as a nonhormonal method), have no impact on sexual function, except in the area of sexual arousal.

\section{Strengths and weaknesses of the study}

This was the first time that we evaluated the sexual function of women in Iran who use the withdrawal or the OCP method. In our study, the level of hormones was not measured. More studies in this field are suggested.

Source of funding: This paper was one part of the research project with the number: rhprc9304, and financial support was provided by the Deputy Vice-Chancellor for Research Affairs of the Ahvaz Jundishapur University of Medical Sciences.

Conflicts of interest: The authors declare no conflicts of interest.

\section{References}

1. Stephenson KR, Meston CM. The conditional importance of sex: exploring the association between sexual well-being and life satisfaction. J Sex Marital Ther 2015; 41(1): 25-38.

2. Cayan S, Yaman O, Orhan I, et al. Prevalence of sexual dysfunction and urinary incontinence and associated risk factors in Turkish women. EBCOG 2016; 203: 303-308.

3. Chen CH, Lin YC, Chiu LH, et al. Female sexual dysfunction: definition, classification, and debates. Taiwan J Obstet Gynecol 2013; 52(1): 3-7.

4. Graziottin A, Serafini A, Palacios S. Aetiology, diagnostic algorithms and prognosis of female sexual dysfunction. Maturitas 2009; 63(2): 128-134.

5. Nappi RE, Albani F, Vaccaro P, et al. Use of the Italian translation of the Female Sexual Function Index (FSFI) in routine gynecological practice. Gynecol Endocrinol 2008; 24(4): 214-219.

6. Melmed S, Polonsky KS, Larsen PR, et al. Williams textbook of endocrinology. 13th ed. Elsevier Health Sciences; 2015.

7. Jha S, Thakar R. Female sexual dysfunction. Eur J Obstet Gynecol Reprod Biol 2010; 153(2): 117-123.

8. Kalmbach DA, Ciesla JA, Janata JW, et al. The validation of the female sexual function index, male sexual function index, and profile of female sexual function for use in healthy young adults. Arch Sex Behav 2015; 44(6): 1651-1662.

9. Santoro N, Worsley R, Miller KK, et al. Role of estrogens and estrogen-like compounds in female sexual function and dysfunction. J Sex Med 2016; 13(3): 305-316.

10. Davis SR, Worsley R, Miller KK, et al. Androgens and female sexual function and dysfunction findings from the Fourth International Consultation on Sexual Medicine. J Sex Med 2016; 13(2): 168-178.

11. Morroni C, Heartwell S, Edwards S, et al. The impact of oral contraceptive initiation of young women's condom use in 3 American cities: missed opportunities for intervention. PLoS ONE 2014; 9(7): e101804.

12. Tracy JK, Junginger J. Correlates of lesbian sexual functioning. Res J Women Health 2007; 16(4): 499-509.

13. Shindel AW, Ferguson GG, Nelson CJ, et al. The sexual lives of medical students: a single institution survey. J Sex Med 2008; 5(4): 796-803.

14. Hatami HAH, Nozadi M, Parizade M. Textbook of republic health. 2nd ed. Tehran: Arjmand pub; 2009: 1598.

15. Speroff L, Fritz MA. Clinical gynecologic endocrinology and infertility. 8th ed. Philadelphia: Lippincott Williams \& Wilkins; 2015.

16. Azari S, Shahnazi M, Farshbafkhalili A, et al. Reasons for choosing the traditional method (Withdrawal) as contraception among women in Tabriz/Iran. IJWHR 2014; 2(5): 297-300.

17. Mohammadi K, Heydari M, Faghihzadeh S. The female sexual function index (FSFI): validation of the Iranian version. Payesh 2008; 7(3): 269-278.

18. Hayes RD, Dennerstein L, Bennett CM, et al. Relationship between hypoactive sexual desire disorder and aging. Fertil Steril 2007; 87(1): $107-112$

19. Malmborg A, Persson E, Brynhildsen J, et al. Hormonal contraception and sexual desire: a questionnaire-based study of young Swedish women. Eur J Contracept Reprod Health Care 2016; 21(2): 158-167.

20. Boozalis A, Tutlam NT, Chrisman Robbins C, et al. Sexual desire and hormonal contraception. Obstet Gynecol 2016; 127(3): 563-572.

21. Warnock JK, Clayton A, Croft H, et al. Comparison of androgens in women with hypoactive sexual desire disorder: those on combined oral contraceptives (COCs) vs. those not on COCs. J Sex Med 2006; 3(5): 878-882.

22. Zimmerman Y, Eijkemans M, Bennink HC, et al. The effect of combined oral contraception on testosterone levels in healthy women: a systematic review and meta-analysis. Hum Reprod Update 2014; 20(1): 76-105.

23. Hollingsworth M, Berman J. The role of androgens in female sexual dysfunction. Sex Reprod Menopause 2006; 4(1): 27-32. 
Tables: 2

Figures: 0

References: 23

Received: 7.06.2018

Reviewed: 26.06.2018

Accepted: 17.08 .2018

Address for correspondence:

Zahra Abbaspoor, PhD, Assoc. Prof.

Department of Midwifery

Reproductive Health Promotion Research Center

Ahvaz Jundishapur University of Medical Sciences

Ahvaz

Iran

Tel.: +9833738331

E-mail: abbaspoor_z762@yahoo.com 